\title{
Theoretical Review of Scientific Approaches to Understanding Crisis Psychology
}

Olga I. Efimova

\author{
Valentina B. Salakhova \\ Irina V. Mikhaylova \\ Svetlana B. Gnedova
}

Tatyana A. Chertushkina

Emiliia R. Agadzhanova

Ulyanovsk State University, 432017, Ulyanovsk, Russia

Email: valentina_nauka@mail.ru

\section{Doi:10.5901/mjss.2015.v6n2s3p241}

\begin{abstract}
The importance of the studied problem is conditioned by the fact that the problem of psychological crisis and its solutions steadily attracts attention of both domestic and foreign researchers from various spheres of the scientific knowledge (psychology, philosophy, pedagogics, and sociology). However, the insufficient development of the psychological crisis concept in theoretical and, in particular, in the empirical aspect contradicts the high practical value of this problem when it comes to the psychological knowledge. The purpose of the article is to define the concept of psychological crisis. In our theoretical and empirical studies we assume that "experiencing psychological crisis" by the individual represents a complicated multidimensional phenomenon that develops depending on various circumstances of life. Possessing intrapersonal and social components within its structure, the phenomenon of psychological crisis has multiple interpretations and draws attention to investigations of both social and psychological factors, and personal matters that define the given phenomenon. Considering the multidimensional character of the studied object, the leading approach to the investigation of this problem is represented by the integrative interdisciplinary approach, based on contemporary domestic and foreign researches in the sphere of general, social and penitentiary psychology, cognitive science, mathematical psychology and other study concepts. The main goal of the article is to define the psychological crisis concept and to work out a methodological program for empirical study. The content of this article shall be useful when applying the empirical studies in the sphere of psychology of experiences.
\end{abstract}

Keywords: psychological crisis, risk of suicidality, difficult life situations, personal semantic sphere and sphere of the values, cognitive attributes, crisis experience, personal and adaptative potential, hardiness.

\section{Introduction}

The problem of psychological crisis is constantly attracting attention of both domestic and foreign researchers from various spheres of the scientific knowledge (psychology, philosophy, pedagogics, and sociology). However, despite its wide use in the scientific literature and on practice, the concept of psychological crisis remains poorly developed from the theoretical viewpoint. Nowadays the methodology of a given problem does not possess a unified basis, and is founded on a number of separate concepts (Freud, 1991; Adler, 1995; Perls, 1997; Assagioli, 1994; Rogers, 1994, etc.); the concept of crisis has no accurate dictionary definition (Meshcheryakov, Zinchenko, 2003) that is, firstly, an abusive neglect, and secondly, testifies to the poor structure of scientific knowledge concerning the psychological crisis matter. Thus, the insufficient development of the crisis issue contradicts the high practical value of this sphere of knowledge.

Usually the empirical studies of psychological crisis were conducted within a certain "vacuum" surrounding, disregarding the real social situation, which an individual find himself in, and cognitive functions of a person.

Moreover, in the sphere of contemporary psychological science there is no the common viewpoint concerning neither the essence of such terms as "complexity"/"difficulty" and "situation", nor their structural and substantial content, and attributing the complexity status to these situations. Each one of the given concepts is controversial; however, there are very few fundamental integrative works capable of giving more or less strict scientific clarification to the abovementioned terms. 


\section{Methodological Framework}

The article of E. Lindemann (1984), dedicated to the acute grief analysis, is considered to be a starting point of the crisis psychology study. J. Jacobson (1974) dealt with distinctive features of the crises' theory. It was J. Kaplan (1963) who described four consecutive crisis stages. Today the leading European scientists also work on development of the similar problems connected to the psychological crisis experience within various aspects. The analysis of empirical studies conducted by the European researchers makes it possible to speak about fragmentary nature of the problem under study and explicit "psychiatric" approach when explaining the origin of psychological crisis and its symptoms. For instance, Professor Clark and his colleagues from the Oxford University study the psychological disturbances of the individual which are the result of psychological crisis experience; scientists from the University of Ulster (Great Britain) work on the factors and mechanisms of intimidation as well as on a victimization problem at school that can lead to a crisis development. The problem of studying an addiction which is as result of crisis experience is more acute for France. A. Quiamzade from the Geneva University (Switzerland), studies the attributive processes which, in our opinion, can be a factor of perception of a situation as critical and irresolvable one. The empirical studies of the American scientists are concentrated on mostly studying of a place of various factors when a crisis situation arises. For instance, there are the studies conducted at the University of Kansas dedicated to a problem of direct and indirect aggression at children's and teenager's age that can cause the crisis outbreak. The work of the American psychological association specialists is focused on studying of problems of risk assessment accuracy for recurrence of sexual violence, abuse at school and psychosocial factors that can contribute to the crisis development. Jean-Paul L'Huillier from the University of Massachusetts, the USA, and Malia F. Mason, Michael W. Morris from Columbia University, the USA, investigate various cognitive processes that, in our opinion, can form a certain view of life situations and their interpretation as simple or critical.

The concept of social deviations of R. Harre (1977) and the voluntary risk behavior theory of S. Ling (1993) are worth mentioning as well. The studies of these scientists allow estimating the consequences of psychological crisis experience. At the University of Virginia they study the sources and mechanisms of morality and ethics (The Origins of Morality) which, in our opinion, can lead to a certain view of the arisen problems and, thereby, inhibit the psychological crisis formation.

The matter of psychological crisis is interdisciplinary problem and draws attention of both philosophers and psychologists at all times. During the era of economic turbulence embracing public misbalance, this problem becomes particularly important for the psychological aid to the people, who are in crisis, as well as for the serving theory. The broad social context of psychological science defines the main branches of its development, inducing researchers to the analysis of various forms of the diverse crisis phenomenon on each stage: problems of freedom and responsibility (Maslow, 1982; Rogers, 1994; Frankl, 1990; Yalom, 1999; Langle, 2010), problems of loneliness (Fromm, 1992), problems of existential vacuum (Frankl, 1990), etc. Crisis as a landmark in life, as a milestone event, which gives to a person, on the one hand, possibilities of achievement of new tops, and on the other hand, risk of falling into the abyss, serves as a key category for understanding of a phenomenon of a personal life journey (Rubinstein, 2004; AbulkhanovaSlavskaya, 1991).

It is worth noting that, if based on the views of many contemporary authors, the psychological crisis condition can develop extremely fast, nearly instantly (for example, when getting the news of someone dear's death), or can be formed gradually starting with a stress state (Zagaynov, 2007; Vasilyuk, 1984). In the scientific world the great attention is paid to the analysis of critical situations that, as according to the classification of F.E. Vasilyuk, domestic scientist, (1984), are divided into stressful, frustrating, conflict and crisis ones. In his works, in "Experience of a grief", in particular, F.E. Vasilyuk described fast formation of psychological crisis. F.E. Vasilyuk interpreted the notion of crisis as a personal collision with the overwhelming obstacles, such as loss of the loved one, job loss, and health breakdown. F.E. Vasilyuk called the overcoming process as "experiences", having filled this term with new sense. Earlier the experience was connected to the emotion that reflects the relation to a person or a factor causing it. F.E. Vasilyuk considers experience to be an intrapersonal work on serenity of mind recovery, adding a new sense to the human activity after overcoming the critical situation. R. A. Akhmerov (1994) introduced into psychology the concept of the personal biographic crises. By the biographic crisis he meant a peculiarity of an inner world of a person which is expressed in various forms of personal emotional experience caused by "non-productiveness' of his/her life journey.

Most authors agree that the psychological crisis can develop from a growing stress condition (Nayenko, 1976; Nemchin, 1983; LKitayev-Smyk, 1983). There are several approaches to the stress factors study in foreign psychology. First is the approach based on the essential life events study, according to which any change affecting human life dramatically is stressful and requires adaptation. According to this approach the essential life event represents a discrete 
change in the social and personal surrounding of a subject. Second is the approach in which chronic stress factors are investigated, and emphasis is put on stressors that can be found in everyday life of the person, but may not seem to him as an annoying trouble. The third is transactional approach, developed by the R. Lazarus (1973), involves studying of difficult everyday life situations. He and his colleagues criticize the previous approaches for their limited ability to predict the illness and poor interpretation of the processes through which the life events may influence health status.

Some authors assume that critical condition can develop under frustration (Silbermann, 1974; Levitov, 1964) or the inner personal conflict (Afonkova, 1974; Yashchenko, 1969). The inner conflict presupposes rather complicated inner world of a person and compliance of this world to the life requirements.

In foreign psychology conflict situations have been investigated within various approaches. For instance, the authors of the psychodynamic concept define conflict as the actualization of two and more motives arising simultaneously. Behaviourists claim that it is possible to speak about the conflict only when there is an alternative opportunities for reaction. Cognitive approach followers claim that the consciousness phenomena clash within a conflict. Domestic authors also contributed a lot to the development of this problem, being based on the activity approach of psychology.

Heavily based on I.R. Konzhin's (2003) works, we are offering the following scheme of development of a difficult life situation capable to lead to a psychological crisis. The principal constituent of a difficult situation is a desire or need that meets objective hardship. The vain attempts to overcome this difficulty lead to a growing mental stress. Within the process of situation development the need importance is estimated that leads to the situation being perceived as complicated, and shifting the motive of a need realization to that of overcoming a difficult situation. Implementation of a strategic choice can come into a need realization and changing a situation, personal contentment from overcoming the hardship.

Despite the fact that there exist various approaches to the psychological crisis development, mental stress and complexity of a situation are its common features. Mental stress shows the peculiarities of mental activity by influencing it when acting in difficult situations. It is complication of the activity conditions that become especially important for a person.

We understand a difficult situation as a set of the objective and subjective characteristics that are gathered in the extremely negative emotional experience of a subject. However, it can be stated that the person's behavior in a crisis situation (constructive overcoming, change of attitude, value sphere and semantic sphere, and, as possible consequences, suicide, deviant behavior, etc.) depends not only on the objective situational characteristics, but also on the subjective perception by the personality that allows the contemporary researchers study the attributive processes of the individuals finding themselves in a psychological crisis.

Thus, the state of psychological crisis leads to the full or partial transformation of the personality of an adult, and in the case of a teenager it leads to the peculiar personality formation and the peculiar formation of process of learning of the world.

For example, from the researchers' viewpoint, experiencing the psychological crisis leads to transformation of a personal value system. The great attention within the frames of philosophy is given to the development of the value system's problems (Tugarinov, 1960; Zdravomyslov, 1996; Drobnitsky, 1967; Vyzhletsov, 1978; Zamotayeva, 2004). The clash of value system with the situation assessment, personal unwillingness to uphold the life values and realize them in uncomfortable conditions can lead to the following consequences: the clash of values causing the lowering of the aspiration level; value system not matching with the personal opportunities and abilities that causes searching of change of the situation; the complicated situation leads to a difficult transformation of all the value system; the difficult situation leads to dissimulation; failure to realize the life values leads to the personal passivity.

A large number of works, both in domestic, and in foreign psychology is dedicated to a problem of value system (Havighurst, 1976; Kohlberg, 1976; Lerner, 1988; Davis, 2003; Mid, 1988; Vasina, 1993; Sayko, 1986; Kirillova, 2000; Molchanov, 2007; Dyudyukina, 1998; Yakimovich, 1990; Bochkaryova, 1980; Yanitsky, 2000; Luneev, 1986; Zvyagina, 2006; Plugina, 2005; Vasilyeva, 1997; Kovalyova, 2003; Stepanova, 1998; Svetlova, 2003; Shestopalova, Perevoznaya, 2003; Bolotova, 2001; Smotrova, 2005; Gritsenko, 2009; Zubova, 2007). The following works are dedicated to the study of structure of the value systems' age dynamics, their relations with the personality characteristics, individual and typical features, professional orientation: E.F. Rybalko, 1974; N. A. Volkova, 1983; V.A. Tokareva, 1989; I.V. Dubrovina, 2003; T.G. Sukhanova, K.D. Shafranskaya, 1982; V. N. Kunitsyna, 2010; N. B. Nesterova, 1984; E.A. Vasina, 1993. There is a branch of study devoted to the investigation of value system that finds the connection between the teenagers' problems of values and those of communication (Dodonov, 1978; Prokopyev, 1987; Gurina, 1995; Ratinov, 1967). Idea of a personality value system as a hierarchy of his/her beliefs is highly spread in the American social psychology (Rokeach, 1973; Schwartz, 1987; Bilski, 1990). 
Experience of psychological crisis can lead to change in the personal attitude, or (as in case of teenagers) formation of the deviant attitude. The fundamental studies of the attitude within a personality system can be found in foreign (Allport, 1958; Rokeach, 1973; Festinger, 1957; Znanetsky, 1981; Thurstone, 1928; Myers, 1996; Smith, 1947; Katz, 2005 and many others) as well as in domestic social psychology (Asmolov, 1990; Uznadze, 1966; Andreyeva, 1978; Nadirashvili, 1987; Feldstein, 1994; Devyatkin, Yadov, 2002 and many others).

Change of personal attitude as a result of the experience of psychological crisis by the subject can lead to the formation of delinquent behavior. For instance, in judicial and penitentiary psychology the problem of psychological crisis among the convicts when enduring the punishment is generally considered as a problem of studying of the prisoners adaptation abilities in custody (Antonyan, 1998; Guldan, 1991; Debolsky, 1994; Efremova, 1988; Kudryavtsev, 1989; Morogin, 1997; Pozdnyakov, 1998; Ratinov, 1967; Samovichev, 1986; Filonov, 1966; Denhoff, Kikkendall, Nye, 1973, etc.). The separate questions connected to the problems of disadaptation, adaptation and readaptation of a personality in prison are reflected in works of the pedagogical psychologists (socialization in the complicated environment), judicial psychologists (psychological essence of crime and punishment), penitentiary psychologists (psychology of a person serving a sentence) (Berezin, 1978; Belichev, 1993; Korolenko, 1972; Sokolov, 1989; Panin, 1981; Ushatikov, 1998; Aleksandrovsky, 1996; Alferov, 1993; Gernet, 1925; Eminov, 1998; Potemkina, 1993; Antonyan, 1998, etc.). However the analysis of scientific literature allows claiming that when studying the most difficult problems of psychological crisis the question of specific character of the social and personal resources of the convicts providing the efficient process of overcoming the stressful influence of the prison environment is nearly neglected.

Experience of psychological crisis can also lead to the self-injurious behaviour of a personality. The problem of self-aggressive behaviour became recently one of the most actual problems in psychology and psychiatry. As many authors believe, heteroaggression and self-aggression possess common pathogenetic mechanisms, and the shaped aggressive behavior can spread either on people around, or to the person itself. For this reason the self-injurious behavior is considered not only as the actions aimed at causing some damage to the somatic or mental health but also as an alternative for the aggressive behavior in which the subject and the object of aggression coincide (Ambrumova, Tikhonenko, 1980; Bacherikov, Zgonnikov, 1989; Pilyagina, 2004). There is no doubt that one of the types of selfaggressive behavior is the self-injurious (self-destroying) behavior at which the voluntary death isn't considered to be a goal. According to many scientists one of the reasons for self-injurious behavior is the problem of identity crisis (Agarkov, 1993; Vasilyuk, 1984, 1995). According to the crisis theory of J. Kaplan (1963), psychological crisis is considered to be a personal state caused by facing an obstacle that the person is unable to overcome using the means he/she knows about at the present moment. In this situation the homeostasis state is broken, and the psychological mechanisms necessary for its preservation do not work, and, thus, come the feelings of confusion and chaos in internal life. Being in such condition the person is disposed to choosing the self-injurious way of overcoming of crisis.

With its relative independence the concept of crises owes not so much to the theoretical peculiarities, as to the practice of a short-term and generally available (unlike expensive psychoanalysis) psychological-mental aid to a person found himself in a critical situation, which is being highly developed in many countries. This concept is an integral part of the mental health service, crisis preventative programs, etc. explains both its obvious advantages such as direct interchanges with a practice, clinical specificity of the concepts, and not less obvious shortcomings such as eclecticism, poor development of its own system of categories and not clear connection between the concepts in use and the academic psychological representations. Therefore it is still too early to talk properly about the psychological theory of crises. However we make will venture to claim that the category of the individual life, which shall be understood as unfolding unity, as a course of the personal life, has to become a backbone category of this future concept (if it is bound to be developed). Strictly speaking, a crisis represents the crisis of life, the critical moment and a landmark of a life journey.

\section{Results}

Though the problematics of individual life crisis has always been in the field of attention of humanitarian thought as well as psychological, the theory of crises has emerged on the psychological horizon rather recently as an independent area of research developed generally within preventive psychiatry. The theoretical review of literature of domestic and foreign authors enables us to draw the conclusion on the lack of uniform approach to understanding crisis psychology and crisis experiences. In this regard we consider the interdisciplinary empirical study devoted to investigation of factors, indicators and determinants of psychological crisis to be necessary. Taking into account the fact that any crisis contains both a positive, and a negative constituent, and can be resolved in various ways including destructive ones, the special attention while drawing up the program of empirical study needs to be paid to identifying suicide behavior of the personality as to a 
way of resolving a crisis life situation, and also to intra personal trigger mechanisms of suicide, to personal and social, psychological factors, causing a choice of self-injurious forms of behavior. The investigation focused on studying social and psychological crisis experience determinants, devoted to a problem of the analysis of causal attribution process in difficult real life situations which directly influences emergence and dynamics of psychological crisis of the personality has to be the other area of research, in our opinion. Along with it research interest has to be concentrated on studying the resources of the personality enduring psychological crisis, in particular on a problem of hardiness which belongs to the categories of psychology that expand the explanatory potential of phenomenology of formation, the personality adaptation, coping behavior and the solution of the difficult life situations that the person faces.

Thus, the need of conducting empirical study of a problem of crisis psychology is determined by its interdisciplinary character and attempt to conduct cross-disciplinary research of contemporary psychology (psychology of the personality, social and clinical psychology). That will allow us to unite such problem areas of study as psychological crisis, suicide risk, the valuable and semantic spheres of the personality, attributive processes, and hardiness of the personality and personal resources of recovery from the crisis. Considering the importance of a practical component in contemporary psychological science, importance of studying the declared problematics is determined also by that fact that the identification of social and psychological suicide factors or, on the contrary, success factors of the person's adaptation in present life conditions, can be used in organizing various forms of effective psychological assistance for the purpose of "coping" with difficult life situations.

To solve the designated problem we developed a program of empirical investigation based on the combination of the following methods:

1. The theoretical analysis of the existing concepts, approaches to the problem of psychological crisis, hardships and attributive processes of the personality, phenomenology of suicidal behavior, resources of the personality in overcoming psychological crisis;

2. The empirical informationcollection characterizing and reflecting the research problem (psychodiagnostic instruments, interviewing, survey, observation).

The structure of the psychodiagnostic part is conditioned by certain empirical research tasks with the use of the following psychodiagnostic instruments:

- the Sixteen Personality Factor Questionnaire by Raymond B. Cattell (16PF), C-Factor (Emotional Stability) aimed at studying individual psychological features of the personality;

- the Rokeach Value Survey (RVS) aimed at studying the personality orientation (terminal and instrumental values);

- $\quad$ the morphological test of vital values (MTGZ) tested by V.F. Sopov and L.V. Karpushinadirected at studying motivational and valuable personality structure. Value systems (A personality profile) and universal basic human values (The review of values) serve as estimation scales;

- the questionnaire of studying personality values by Sch. Schwartz (tried out by V. N. Karandashev) aimed at studying individual personality values. Vital fields and vital human values serve as the estimation scales;

- the technique of polymotivational tendencies diagnostics in I-concept of the personality by $\mathrm{S}$. M. Petrovdirected at studying the motivational sphere of the personality;

- the multilevel personal questionnaire Adaptability (MLO) by A.G. Maklakov and S.V. Chermyanin aimed at studying psychophysiological, social and psychological characteristics of the personality (personal and adaptive potential);

- self-relation questionnaire (OSO) by V.V. Stolin and S.R. Pantileyev aimed at the personal self-relation study;

- the limiting meanings method (TLM) by D.A. Leontyev and V.N. Buzin oriented to the study of the dynamic semantic systems (DSS) of the personality. The estimation scales are limiting categories (meanings) of personal world outlook;

- the modified version of the repertory grid by George Kelly aimed at the study of causal attribution processes and self-attribution;

- the experimental psychological technique of studying the frustration reactions by S. Rosenzweig oriented to identification of causal attribution types;

- the Interpersonal Diagnosis of Personality by Timothy F. Leary aimed at studying self-attribution processes. The subjective well-being scale was used as an accessory instrument for studying self-attribution;

- $\quad$ hardiness test by Salvatore R. Maddi (adapted by D.A. Leontyev);

- the technique of Training motivation in higher education institution by T.I. llyina directed at determining educational professional activity motives;

- biographical method; 
3. the methods of statistical analysis of obtained results including the use of the following statistical methods:

- $\quad$ the Mann-Whitney $U$ test;

- Student's t-test by William Sealy Gosset;

- theKolmogorov-Smirnov test;

- $\quad$ The Wilcoxon signed-rank test;

- $\quad$ An F-test by Ronald A. Fisher;

- the Pearson product-moment correlation coefficient;

- Factor analysis by means of principle component analysis with the curve of factor axes by means of Varimax method.

Initial methodologic positions, tried out instruments, research representativeness of sample and statistical analysis of the results with the use of the computer statistical analysis programs provide reliability and validity of the study results.

The choice of the mentioned research techniques is conditioned by the fact that the mentioned techniques allow to study all the constituents of living through the psychological crisis process, representing a wide and various range of research instruments.

Work plan;

Stage 1.

An important part of the developed program of empirical study is a thorough preparation for developing the complex theory of the studied psychological crisis phenomenon and practical investigation, the analysis of the existing theoretical basis of the existing preliminary studies. This will allow us to determine the weak points of already existing theories and to specify the features of our empirical study realization.

The focus of our interest covers various difficult reality situations connected with such fields as family, work, study, leisure activities, intimate and personal relations, relaxation. The researches in this field may be used theoretically, which allows to reveal the evident and latent schemes of cognitive process in critical situations and their conditions.

Certain types of activity at the first stage of the project implementation: The analytical review of applied research material on the outlined problem. The development and specification of the methodical instruments, the instruments' preparation for the investigation (test forms, the order of testing techniques, the materials' replication).Organizational preparation of the empirical study (making direct contacts and arrangements with the organizations where all the investigation phases will be carried out).Sampling procedure. The study of documents (medical reports in the toxicological department of Ulyanovsk emergency hospital, criminal cases), interviewing and inquiring the staff of the Sentence Execution Department.Pilot studying.Primary processing of results.Preparation of the publications according to the theoretical analysis results.

As a result of our activity at the first stage we are going to:

- analyze theories of the Russian and foreign authors covering the problem of psychological crisis experience, cognitive attributes of the process, suicidal risk and hardiness;

- examine the reality situation concepts in modern science thoroughly;

- correct the plan of all psychological crisis constituents' investigation on the basis of theoretical material;

- -thoroughly examine concepts of personal adaptive potential and personality measures' dynamics in contemporary science;

- -specify the psychological crisis concepts, suicidal risk and hardiness concepts in the context of penitentiary psychology; determine overcoming factors of the prison environment psycho-traumatic influence ;

- study thoroughly the theoretical and empirical methods determining features and mechanisms of the personality's adaptation processes of a convict and criminal behaviour strategy in the conditions of imprisonment in the context of crisis psychology;

- correct on the basis of theoretical and empirical materials the investigation plan of the problem covering the psychological crisis experience by a convict (existential crisis, loneliness crisis, social isolation crisis, etc.);

- $\quad$ prepare the interim study report.

Stage 2.

The second stage of the mentioned project implementation is an empirical stage and, definitely, the most important one. Being implemented according to the preliminarily prepared plan based on the conclusions made at the first stage, and the concepts introduced while working out the investigation structure, it allows us to state, with proper approach to information processing, about the achievement of potentially significant results.

Certain types of activity at the second stage of the project implementation:

Complex empirical investigation on the basis of Ulyanovsk emergency hospital, the regional mental hospital named 
after N.M. Karamzin, Novoulyanovsk Federal Penitentiary Service of the Russian Federation, Ulyanovsk and Dimitrovgrad psychological assistance centers, particularly the investigation of personal, social and psychological features of the people overcoming psychological crisis, the emotional and volitional field, the valuable and semantic field, personal and adaptive potential of various examinee categories (suicides, disabled people, prisoners), identification of anti-suicide potential factors of the personality, social and psychological factors of a personal suicide choice, suicidal risk factors of the personality.

The investigation results at the second stage will be the following:

- the empirical and experimental investigation programs directed at cognitive attributes' identification in difficult reality situations will be developed;

- thepilot and main study in all directions of the project implementation will be conducted;

- thepsychodiagnostics of all examinee categories with the use of the mentioned methodical instruments will be carried out;

- on the basis of the obtained results preliminary conclusions will be drawn;

- the interim study report preparation.

Stage 3 .

The third stage is the final stage and it is connected with the interpretation of the obtained results and their use in certain conclusions for particular human activity fields. These conclusions may be checked by means of additional empirical investigations so that one could be sure of their relevancy and could develop recommendations for application.

The obtained data processing, its systematization and interpretation will allow to prove statistically the conclusions' validity on the basis of which there will be developed attribution patterns in difficult reality situations, psychological crisis overcoming pattern and the choice of the way to overcome it, and vital resources pattern as ability to adapt to the community life norms in the form of emotional and sensual experience.

The investigation results at the second stage will be the following:

- on the basis of the theoretical and empirical investigations the main conclusions in all directions of the project implementation will be drawn;

- the cognitive attributes and factors by means of which the individual identifiesthe degree of situation complexity will be determined;

- the recommendations for weakening possible negative consequences and weakening certain negative cognitive attributes in difficult reality situations will be developed;

- the pattern of attribution in difficult reality situations will be developed;

- the psychological crisis overcoming pattern and the choice of the way to overcome it will be developed;

- the pattern of vital resources as abilities to adapt to the community life norms in the form of emotional and sensual experience will be developed.

\section{Discussions}

Our analysis of theoretical and empirical studies, conducted by both Russian and foreign authors, allows us to draw a conclusion that now the personal crisis problem, despite its wide use in special literature and practice, remains insufficiently developed in the theoretical aspect. Based on a range of separate concepts the outlined problem methodology has no universal criteria. The crisis concept has no accurate dictionary definition. The psychological crisis development and dynamics are also viewed by different authors in different ways. Many modern authors consider that psychological crisis may develop very rapidly, almost instantly (e.g. after the death of a beloved and significant person), or it may be formed gradually, stimulated by a stressful condition.In the different theories different factors are considered to be the determinants, causing the development of psychological crisis. These can be stressors (according to Nayenko, 1976; Nemchin, 1983; Kitayev-Smyk, 1983), frustration (Zilberman, 1974), internal conflicts (Afonkova, 1974; Yashchenko, 1969), period of facing obstacles (Kaplan, 1963). The concepts of psychological crisis experience, worked out by both the Russian and foreign scientists are also different. Some of them consider that experience of psychological crisis causes the alteration of the personal value system (Tugarinov, 1960; Zdravomyslov, 1996; Drobnitsky, 1967; Vyzhletsov, 1978; Zamotayeva, 2004). Experience of psychological crisis can change personal attitude, or cause development of (speaking about teenagers) deviant attitude (Gordon Allport, 1958; Rokich, 1973; Festinger, 1957; Znanetsky, 1981; Louis Thurstone, 1928; David Myers , 1996; Smith, 1947; Katz, 2005; Asmolov, 1990; Uznadze, 1966; Andreyeva, 1978; Nadirashvili, 1987; Feldstein, 1994; Devyatkin, Yadov, 2002 and many others). The change of personal attitude as a result of psychological crisis experience can cause development of delinquent behavior (Antonyan, 1998; Guldan, 1991; Debolsky, 1994; Efremova, 1988; Kudryavtsev, 1989; Morogin, 1997; Pozdnyakov, 1998; Ratinov, 1967; 
Samovichev, 1986; Filonov, 1966; Denhoff, Kikkendall, Nye, 1973, etc.). Psychological crisis experience can also stimulate self-injurious behaviour of the personality (Ambrumova, 1989; Tikhonenko, 1980; Bacherikov, 1989; Zgonnikov, 1989; Pilyagina, 2004; Agarkov, 1993; Vasilyuk, 1984, 1991, 1995).

However, despite the variety of approaches to psychological crisis, we consider that its universal criterion is mental tension and situation complexity. Mental tension expresses the features of mental activity in difficult conditions in the process of action. It influenses the efficiency of mental activity complicating the activity conditions which gains in particular importance for the personality. The scheme of a difficult reality situation which can cause psychological crisis, in our opinion is the following: difficult reality situation is the result of the clash between the need and the objective obstacle. Unsuccessful attempts of overcoming the obstacle result in the growth of mental tension. As the situation develops, the importance of needs is estimated which makes the individual consider the situation as a difficult one, the motive of need implementation is changed by the motive of overcomingthe most difficult situation. The strategic choice may come to the need implementation and the situation changing, personal satisfaction from overcoming the obstacle. We consider the difficult situation as a set of objective and subjective characteristics presenting together an extremely negative emotional experience for the individual. Besides, the individual behavior type in a crisis situation (constructive overcoming, change of attitudes, change of valuable and semantic field and then possibly a suicide, deviant behavior, etc.) depends not only on objective situation characteristics, but also on the subjective perception of the personality which makes scientists now study attributive processes of the individual in psychological crisis.

Thus, the psychological crisis causes full or partial transformation of the adult's identity, and speaking about the teenager's identity - to a peculiar personality formation and a peculiar way of world perception.

The concept of crises owes its relative independence not so much to its own theoretical features, but to the fact how much its constituents become part of a short -term practice intensively developing in many countries and available to broad segments of the population (unlike expensive psychoanalysis) psychological and mental health services to the person who found himself in a critical situation. This concept is inseparable from the service of mental health, crisis and preventive programs, etc. that explains both its evident advantages - direct interchanges with practice, clinical concretion of concepts, and not less evident shortcomings - eclecticism, lack of its own system of categories and non-elucidation of the link between the used concepts and academic psychological conceptualization. Therefore, it is too early to tell something about the psychological theory of crises in the true sense. However, we are so bold as to state that the category of the individual life which is understood as the unfolded whole, as a course of life of the personality has to become the cornerstone category of this future concept (if it is destined to take place). As a matter of fact, crisis is a crisis of life, the critical moment and a turning point of a course of life.

\section{Conclusion}

The made review of theoretical and empirical studies on a problem of crisis psychology allowed us to draw the conclusion that the problem of psychological crisis and ways of its solution are steadily attracting attention, of both domestic and foreign researchers in various areas of scientific knowledge. However, the insufficient investigation of the concept of psychological crisis in theoretical and especially in the empirical plan is in conflict with the high practical importance of this problematics in psychological area of knowledge. This fact testifies to an urgent need of conducting the empirical studies devoted to "experience of psychological crisis" by the personality as a difficult multidimensional phenomenon, differently shown in various life circumstances. Implementation of the presented program of empirical study will allow to fill the shortage of both theoretical, and empirical character which arose round the investigation of problematics of "psychological crisis".

\section{Recommendations}

Materials of this article can be useful to practitioners -psychologists, suicidal behavior specialists and scientists working with the inner world of a person.

\section{References}

Abulkhanov-Slavskaya K.A. (1991) Strategy of life. Moscow: 299

Adler A. (1995) Practice and theory of individual psychology. Moscow: 296

Aleksandrovsky Yu. A.(1996) Borderline psychiatry and modern social problems. Rostov-on-the Don: 111

Asmolov A. G. (1990) Psychology of the personality. Moscow: 302 
Assadzhioli R. (1994) Psychosynthesis: theory and practice. Moscow: 314

Caplan G. (1963) Emotional crises. - 111: The encyclopedia of mental health. NY. vol. 2, pp. 521-532.

Drobnitsky, O.G. (1967) The World of the recovered objects.Problem of value and Marxist philosophy Text. / O. G. Drobnitsky. Moscow: 352

Frankl V. (1990) The man in search of meaning. Moscow: 368

Fromm E. (1992) The soul of a person. Moscow: 430

Harre R. (1977) The ethogenetic approach: Theory and practice // Experimental social psychology. - NY. vol. 10. pp. 283-314.

Kitayev-Smyk D. A. (1983) Stress psychology. Moscow: 370

Levitov N. D. (1964) Of mental conditions of the person. Moscow: pp. 18-35

Lindemann E. (1984) Clinics of acute grief / Psychology of emotions. Texts / Under the editorship of V. K. Vilyunas, Yu.B. Gippenreyter. Moscow: 288

Ling S. (1993) On a razor edge: social and psychological analysis of deliberate risk // Social and humanities. - Domestic and overseas literature. Series 11.Sociology. No. 2. pp. 97-102.

Maslow A. (1982) Self-updating // Psychology of the personality. Texts. / Editors: Gippenreyter Yu. B., Pusyrey A. A., Moscow. pp. 108117.

Myers D. (1996) Social psychology. St. Petersburg: 688

Perlz F. (1996) Gestalt approach and Witness of therapy. Moscow: 240

Rogers K.R. (1994) A view on psychotherapy: formation of the person. Moscow: 480

Rubenstein S. L. (2004) Fundamentals of general psychology. St. Petersburg: 678

Vasilyuk F. E. (1984) Psychology of experience: analysis of overcoming critical situations. Moscow: 200

Yacobson. G (1974) Programs and techniques of crises intervention //American handbook of psychiatry. NY: 825

Yalom I. (1999) Existential psychotherapy. Moscow: 340

Yashchenko M. M. (1969) Problems of impact of hardships on the process of forming moral experience of senior school students. Dissertation of cand.pedagogical sciences. Moscow: 348 